\title{
Targeting Teaching Curriculum and Overall Design Management Based on the "Living Space Design"
}

\author{
Zongyuan Zhang ${ }^{1, a}$, Xinglin $\mathrm{Xu}^{1, \mathrm{~b}}$, Lili Shi ${ }^{1, \mathrm{c}}$ \\ ${ }^{1}$ Qingdao Huanghai University, Qingdao, Shandong, 266427 \\ ${ }^{a}$ email, ${ }^{b}$ email, ${ }^{c}$ email,
}

Keywords: Project Teaching; Living Space Design; Curriculum Reform

\begin{abstract}
In this paper, "the living space design" course, for example, the ability to fully explore the professional work training, professional design capabilities and gradually increase two main courses teaching reform project constructed by integration organization, targeting in determining the curriculum, improve the overall design configuration, make the teaching content tight cut combined with industry companies post tasks, teaching a clear project-oriented requirements for the implementation of the training of relevant knowledge, skills, and complete learning tasks in the appropriate context space, so as to effectively enhance the professionalism and Post awareness.
\end{abstract}

\section{Introduction}

"Living space design" courses are vocational colleges interior decoration design professional curriculum system in the direction of the core curriculum, students are advanced space based high-end design, with pivot roles; while the living space design decoration industry is also important work job requires a lot of professional and technical skills of personnel engaged in related work. In the current industry enterprise innovation means to process materials, management of continuous transformation and upgrading, which gives "living space design" course brings new requirements, the need to find a suitable target location in the field of development and design courses, from to bring the whole professional knowledge and skills students learn at the same time, be able to work through the process and get experience and career awareness methods, cooperative learning through exchanges and learn to communicate and eventually form a comprehensive vocational ability.

At present, Jiangsu province of the Vocational Colleges' living space design "course has begun to adopt a real or virtual project as a carrier, task-driven, situational operation means to implement curriculum reform, this course of study in the field of development and design purposes teachers and students to promote students to construct their own knowledge through a comprehensive joint implementation of a complete project work. To this end we examine some of the excellent course construction projects and materials, we found some curriculum is mainly concentrated in the student's ability to improve the design of professional training, professional ability training for students still lack a systematic design, ignore the needs of students career development and changes . The key is not good for the objectives of the course in the field of accurate positioning, but did not pay attention to the overall design of the project to complete the teaching on the basis of the target location, so stay the course of reform in thinking and slogans stage, the substance has not been content curriculum sexual advance.

\section{Basic Consideration of Curriculum Reform Project Design}

Curriculum development fields of study by the "work process" Export "action areas", and then by teaching integrated to form a "learning areas", and through specific "learning environment" to implement, holistic, collaborative, personalized features [1 ]. Based on this process, the overall design of the course first need to solve two problems, the first is how the job requirements and occupational skills among students to master cognitive growth law to bridge the gap. Through research and participation in the work of some decoration enterprises, we found that companies designers must have two aspects comprehensive ability, on the one hand around customer reception, 
business negotiation skills and quotes, contract work expanded operational capabilities, we call the ability to work as a career post, which contains a designer behind the integrity, compliance, flexibility, efficiency, collaboration, quality values and character requirements. On the other hand is completed around the concrete interior design content corresponding ability to work, there should have included designer software technology, engineering and technology, culture, philosophy and other humanities and technical requirements, which we call the professional design capabilities. Living space designer in the company as a platform to project specific room space for the content of the business activities of practitioners, both capabilities at different stages of the process with projects in different proportion alternately integrated reflected, they show the overall state form the core capability career designers. In view of this, we need a specific item or virtual operations, in the context of the work of these two main lines are woven together in the implementation of the project of teaching, so that students can complete a more comprehensive and integrated design activity in the multi-dimensional perspective cognition and experience, done in the case of workplace stress on the preliminary cognition itself showing the structure of knowledge, ability and character values, adaptation and learning and enhanced.

The second question is how to vocational students based on cognitive rules to select the appropriate specific work items, good choreography organizational design learning programs. First, learn from the current situation analysis of higher vocational students in learning attitude and learning methods, most of the students lively and undisciplined, sensitive but not active, warm feelings and lack of tolerance, but more floating point of interest on the surface, to learn strong frustration, so how reasonable guide students 'interest, to protect students' enthusiasm for learning interior design is a difficult teaching project design. Secondly, it should be noted vocational training objectives and business school teaching job training objectives are different, the prominent characteristics of enterprises employing system is out of the market, but the process of teaching in schools should allow more students to build the future of occupational areas the expertise and experience of the application of cognitive ability and quality of self-experience, which can be more clearly plan their future roads, schools, educational personnel training outstanding feature is "one less." In view of this, organizational design teaching program is a systematic project, from tasking, planning, implementation, inspection report, the appraisal should be a complete closed-loop design of scientific and operational processes. We should be fully aware of the process of teaching both guide students into the line, which is a part of the students' self-ability, personality, interests, and then awareness of the value. Therefore, teaching programs on structural arrangement must be implemented from the point to the surface, from simple to complex, gradual development, to develop the professional ability to protect students' interests and to find a balance between a healthy personality.

\section{The "Living Space Design" Project Targeting Course Teaching Reform}

Since the room space and design projects monomers category is complicated, professional designers and professional operation design capability must be repeated using multiple rounds of exploration work in project operations, its comprehensive work ability of individuals to gradually develop and perfect. Growth in professional activities both capabilities are simultaneous and complementary, generated this ability is similar to the traditional "bamboo weaving forming principle." Therefore, the need to design training course teaching multiple items from two paths to choose and organize teaching programs to make students' comprehensive ability in a time of different design activities in the process to become skilled and promotion.

In both cases based learning pilot analysis and exploration rounds, the teaching of this course is targeting the home improvement business room space design work for core positions, "the posts have the ability, the strength becomes Kong, the development has the potential" for the job training objectives, students follow the basic rule of professional competence and cognitive growth, professional competence based on the work process of culture as the focus, focus on vocational skill and ability to work the room space design capabilities to enhance two main lines, from both horizontal and vertical dimensions students have engaged in interior design industry, 
business-related professional positions needed for the work knowledge, skills, abilities and the basic quality requirements.

Targeting based curriculum, teaching its overall construction idea is through cooperation with industries and enterprises to establish living space designers typically work item types of occupations and modes of operation; relying on the "school-enterprise cooperation studio + project site" for the teaching conditions and the platform to create integration of Teaching, learning and teaching environment; in accordance with the same principles of learning path and working path around the students' professional ability of skilled and professional capacity to grow, integrated package implementation project teaching two paths; school-enterprise cooperation projects and typical tasks for the carrier select course content, to carry out a real project step by step guidance, specific task-driven cycle, the teaching process to learn to do one of the situational training teaching; through scientific evaluation system to help students complete knowledge of the professional positions require actual work tasks, ability and quality requirements of the knowledge and experience, thus achieving an integrated personnel training students' employment and sustainable development capacity of the training objectives.

\section{The "Living Space Design" Course Teaching of the Overall Design of The Project}

Teaching Learning Areas project implementation is inseparable from the specific learning situation design, due to professional knowledge is a soak experience information, and relevant to a particular observer and observation methods [3]. This experiential knowledge may also be referred to as situational knowledge, with individual characteristics and an individual can experience, observation and reasoning for knowledge. Therefore, how to promote students to think of the scenario-based real environment, sustainability is to build students' core elements of the design. The overall design "living space design" Curriculum Reform Implementation Project of teaching vocational knowledge and professional skills of learning is the key to master the specific implementation process, learning situations designed to guarantee the first two, it must be considered and fine focus of.

After more than two of Teaching, this course is a comprehensive situational scenario background and skills training to prepare students for candidate materials decoration business-related professional positions undertaken. Teaching project design follow the "work process analysis selected typical tasks - into learning areas - the design of learning environment," the logic of the main line, referring to business students practice time requirements to complete a semester hours to simulate a living space designer from the entry, use, fully familiar with the business to high-end design to the career growth path. Taking into account students' individual learning ability and interest of differentiation, from simple to follow a comprehensive, this functional is to the creative principle of the individual to the team with the total design of the five projects and the implementation of teaching situations, including a cognitive project, three standard items and a quality Development project.

Start a five projects to guide the overall project throughout both projects is the overall objective of the course, the subsequent four projects are in preparation of materials for the first item, each item by changing the design objects, from single to integrated, to learn to implement an integrated context, students step by step professional design capacity to understand and apply the occupational status of the core operating capacity, after the current close relationship logic to meet growing student cognitive experience to achieve. Overall four months teaching practice, classroom valid for 96 hours.

According to survey results, two students, when students enter the room space design courses, home improvement and design activities in the enterprise designers feel most professional activities is chaos or fragmented, so in practice situations supporting a project design, the need to make full use of its advantages in resources of school-enterprise cooperation platform offered by teachers to lead students to visit local larger scale and strength of the home decor company, first met the company business model and related occupational status group, focused on understanding the decoration designers career growth paths and specific capacity requirements, while study materials technology company model, the establishment of design-conscious materials, technology, cost, 
customer associated with the effect, on the basis of this study, the company designer job candidates to write $\mathrm{CV}$ to explain their business expertise and skills within three years require certificates, honorary certificates and project information designed as a support material. A project to import both courses, also the result of the course, which is to build the future of the workplace and specific perceptual framework to guide students through, causing students to literacy and their ability to compare the relationship between the needs of professional positions, find professional learning sense of direction, motivation and objectives for the purpose of completion of this course can play a catalytic role.

From the design point of view the market is currently experiencing the most practical designer of the chamber is the most common area of about 110 square feet, a clear division of function space three-bedroom apartments, a kitchen and two baths, preferred such projects meet three beginners two requirements: space design difficulty is low, with professional work of universality, design content more complete. Combined with students' cognitive law, professional design modernist design concept as the basis for "comfort design" as the theme, focusing on guiding students to the main living space and planning method using a cognitive function, design follows function design. Teaching situations designed to combine professional job operation process, the preferred real project, requiring students to work in pairs to fill customer Fact Sheet in accordance with the results of communication with customers, agreed to the amount of room-to-door time and location of the project and the cell site comprehensive investigation, analysis and measurement, two weeks or less to complete the routine operation of the main design features. In the teaching project control, guidance teachers to use classroom time to different regions for functional design, also invited some students to explain their design ideas and programs, teachers can be discussed in the process of thinking gradually through workplace design and interactive work experience delivered to students. Project II instructional design feature is to enable students between physical space, customer demand and occupation rules initially established real experience.

From the professional design perspective, the difficulty of small units designed to be higher than the normal size of home design is mainly reflected in three aspects: Alien space and more, younger customer base, functional areas of uncertainty. Therefore, this project teaching situations design in the design basis of experience students have constructed, using virtual project's operation, the students follow vocational post operation path to its own future to think set to start a variety of forms and style of program design in five years to be in demand. Teaching focus is to enhance the students 'ability to organize space, broaden students' design ideas.

Duplex villa residential renovation or home improvement market in high-end products, mostly designers need more than three years of experience before doing the design work, the difficulty of interior design has three aspects: Portrait space coordination difficult, craft and decorative details complicated, high cultural taste customer demand. Therefore Fourth item positioned in the curriculum as a whole session to enhance the students to use their knowledge, comprehensive training quality structure and professional positions to work, teaching situations design selection of a real project, students focus and depth customer communication skills training, strengthening the scene found problems with problem-solving skills, in-depth understanding of marketing decorative "eight style ', combined with customer requirements in a design style themes case design work.

Model Room has its own peculiarities in the living room space design, although the design of the object is still the living space, but it serves the object from a single family or a specific market or region on behalf of individuals into a virtual consumer class family, serving the real estate developer, a real estate marketing planning and positioning of design activities. Its content is designed mainly to design the whole case, it is the "turnkey" design. Therefore, the model room design drawings design quality is different from the home improvement business operation is more akin to professional tooling design ideas and requirements, teaching purpose of this project is to provide students advanced design of public space to prepare. In the design of virtual teaching situations based, according to the cognitive basis students have established a project team consisting of the project to carry out two space redesign, students focus on research and analysis capability, the ability to extract cultural elements, design drawings deepening capability team collaboration 
division of labor and results reporting skills.

\section{Conclusion}

By completing the above four practice project, students of vocational workflow-related professional positions content and quality requirements establish a more three-dimensional Perception; reflected on the structure of their knowledge, expertise and other professional skills, excellent design process shortcomings have a more clear understanding, while some students to their own interests and career direction is also expected to make appropriate adjustments based on this back to allow students to resume control projects and supporting materials requires a careful summary to form a complete academic report, teaching result thus obtained is real, comprehensive and effective.

This from the "work process" Export "action areas", and then by teaching integrated to form a "learning areas", and through the teaching reform specific "learning situation" to be implemented, through the "living space design" project of reform of the curriculum implementation, teaching content tight cut combined with industry companies post tasks, teaching a clear project-oriented requirements to implement the training of relevant knowledge, skills, and complete learning tasks in the appropriate context space, learning knowledge and skills at the same time, effectively enhance the professionalism and job awareness. "Living space design" project-based curriculum reform, so that we can better control the Vocational College Students "can win Gang - solve the employment ability, reorientation - enhance career skills, sustainable development - the potential of multi-skill" This a professional training objectives, better training to adapt to the social development needs expertise.

\section{Acknowledgements}

This article is 2015 Qingdao Huanghai University research topic "Professional Training mode of the studio system in Private Universities Environmental Design - A Case Study of Qingdao Huanghai University " the initial results,

\section{References}

[1] Jiang Dayuan. German vocational education program curriculum learning areas of research[J]. Chinese Vocational and Technical Education, 2007, (02): 47-54.

[2] Wang Guosheng. Service design and innovation[M]. Beijing: China Building Industry Press, 2015.024 